\title{
ADEQUAÇÃO DE ELEMENTOS URBANÍSTICOS AO ESTATUTO DA PESSOA COM DEFICIÊNCIA: O CASO DE PELOTAS/RS
}

\author{
Pablo Alan Jenison Silva ${ }^{1}$ \\ Felisberto Ferreira de Freitas Júnior ${ }^{2}$
}

\section{Resumo:}

Objetiva-se identificar das alterações promovidas na Lei da Acessibilidade e no Estatuto da Cidade com o advento da Lei Brasileira de Inclusão da Pessoa com Deficiência. Além disso, averiguar se o Plano Diretor de Pelotas adequou-se às diretrizes estabelecidas pelo novo marco legal. Debate-se os conceitos e as origens do Direito à Cidade e do Plano Diretor, as transformações ocorridas nos elementos de urbanização e a realidade de Pelotas. Trata-se de um estudo de caso, com procedimento analítico, técnica de pesquisa bibliográfica que utiliza o método de abordagem dedutivo. Concluiu-se que não houve a devida adequação no Plano analisado.

Palavras-chave: Acessibilidade; Direito à Cidade; Plano Diretor; Rotas Acessíveis

\section{SUITABILITY OF URBANISTICS ELEMENTS FOR THE STATUTE OF DISABLED PEOPLE: THE CASE OF PELOTAS/RS}

\begin{abstract}
:
The aim is to identify the alterations promoted in the Accessibility Law and the City Statute WIth the Disability Inclusion Brasilian Law advent. Also, ascertain wheter the Pelotas's Master Plan suited the stabilished guidelines by the new legal mark. DIscussing the concepts and origins of the right to the city and the Master Plan, the urbanization elements's transformation that occured and the Pelotas city reality. Its a case study, therefore the deductive approach was used, with analytics procedure and bibliographic review. Was concluded the city of Pelotas didn't adequate to the analised Plan.
\end{abstract}

Keywords: Accessibility; Right to the city; Municipal Master plan; Accessible Routes

\section{Introdução}

\footnotetext{
${ }^{1}$ Mestrando no Programa de Pós Graduação em Direitos Sociais da Universidade Federal de Pelotas - UFPel. Bacharel em Direito pela Pontifícia Universidade Católica de Minas Gerais - PUC Minas. pabloalanjs @ gmail.com.

${ }^{2}$ Mestrando no Programa de Pós Graduação em Direitos Sociais da Universidade Federal de Pelotas - UFPel, Pós graduando em Direito Tributário e Empresarial na Universidade Católica de Pelotas - UCPEL, Bacharel em Direito pela Universidade Federal de Pelotas - UFPel. fdefjunior@hotmail.com.
} 
Nos últimos anos as discussões acerca da acessibilidade têm ganhado ênfase no cenário nacional e ocupado os mais variados espaços de debate. Temática de extrema relevância para o desenvolvimento da cidadania e caracterizada como essencial para a garantia de direitos fundamentais das pessoas com deficiência ou mobilidade reduzida, alcançou as mais diversas ciências, se robusteceu e tornou-se elemento principal de ações públicas dentre as quais destacase a construção de espaços urbanos inclusivos.

Resultado destes debates, a Lei Federal no 10.098/00 - Lei da Acessibilidade, inovou o tratamento da questão, pois estabeleceu normas gerais e critérios básicos para a promoção da acessibilidade. De igual maneira, a Lei no 10.257/2001 - Estatuto da Cidade, promulgado em 10 de julho de 2001, promoveu grande avanço na política de gestão urbana e na busca pelo Direito à Cidade. Nesse seguimento, em 6 de julho de 2015 entrou em vigor a Lei Federal no 13.146 - Lei Brasileira de Inclusão da Pessoa com Deficiência (LBIPD), reconhecida por estabelecer um novo marco para a acessibilidade e por incluir de maneira definitiva as discussões acerca da acessibilidade no Direito Urbanístico. Dessa forma, consagrou como indispensável, a observância de suas diretrizes para a construção de espaços urbanos inclusivos.

Neste contexto, o problema que norteou o presente trabalho envolve discussões da acessibilidade e o Direito à Cidade, tendo em vista que é no ambiente municipal que a segregação das pessoas com deficiência ou mobilidade reduzida é notória. Além disso, considerou-se as informações colhidas previamente no sítio eletrônico do Instituto Brasileiro de Geografia e Estatística (IBGE) cujos dados apontam para a existência de 87.295 pessoas com algum tipo de deficiência no município de Pelotas, no Estado do Rio Grande do Sul, o que representa 25\% de sua população (IBGE,2010).

O presente artigo, tem como objetivo identificar quais foram as alterações promovidas na Lei da Acessibilidade e no Estatuto da Cidade com o advento da LBIPD. Além disso, averiguar, em que medida o III Plano Diretor de Pelotas, adequou-se as diretrizes estabelecidas pelo novo marco legal e assim contribuir para uma melhor compreensão dos debates de acessibilidade.

Para tanto, dividiu-se o artigo em 3 capítulos, que discutem incialmente as origens e conceitos do Direito à Cidade e do Plano Diretor, posteriormente apresentam-se os elementos de urbanização à luz da Lei Brasileira de Inclusão da Pessoa com Deficiência - Lei 13.146/2015, e 
Por fim, realiza-se a análise da adequação do Plano Diretor de Pelotas, aos instrumentos que promovem a acessibilidade e o Plano de Rotas Acessíveis.

A pesquisa caracteriza-se com sendo do tipo explicativa, adota o procedimento de revisão bibliográfica, análise documental e método hipotético dedutivo.

\section{DIREITO À CIDADE E PLANO DIRETOR}

As discussões acerca do Direito à Cidade não são recentes e tampouco se restringem ao âmbito jurídico. Inicialmente a matéria foi objeto de estudos de outras áreas como a Sociologia, a Filosofia e a Geografia. Posteriormente, passou a ser debatido também na Arquitetura e Urbanismo, no Planejamento Urbano e atualmente, com maior ênfase, no Direito, caracterizandoo como disciplina transdisciplinar, fruto de uma construção coletiva e como um direito à produção do espaço.

Na busca pela institucionalização de um conceito para o Direito à Cidade, destaca-se a proposta estabelecida na Carta Mundial pelo Direito à Cidade, oriunda do Fórum Social Mundial Policêntrico, realizado em 2006:

2. O Direito a Cidade é definido como o usufruto equitativo das cidades dentro dos princípios de sustentabilidade, democracia, equidade e justiça social. É um direito coletivo dos habitantes das cidades, em especial dos grupos vulneráveis e desfavorecidos, que lhes confere legitimidade de ação e organização, baseado em seus usos e costumes, com o objetivo de alcançar o pleno exercício do direito à livre autodeterminação e a um padrão de vida adequado. (CARTA MUNDIAL DO PELO DIREITO À CIDADE, 2006).

No âmbito internacional, o marco das discussões encontram-se no lançamento da obra $L e$ Droit à La Ville de Henri Lefebvre lançada em 1968 e reconhecida como pioneira na abordagem do Direito à Cidade. Partindo de sua leitura é possível compreender, que este direito estabelece não somente uma relação qualitativa entre a vivência social no espaço urbano, mas também, a maneira de reprodução de modos de vida em sociedade. Assim, configura-se como "uma forma superior dos direitos: direito à liberdade, à individualização na socialização, ao habitat e ao habitar”. (LEFEBVRE, 2008, p. 134).

Revista de Direito Urbanístico, Cidade e Alteridade | e-ISSN: 2525-989X | Belém | v. 5 | n. 2 |

p. 55 - 71 | Jul/Dez. 2019. 
Por outro lado, no contexto brasileiro, Gomes (2018) aduz que as primeiras discussões do Direito à Cidade surgiram com movimentos sociais urbanos influenciados pelo movimento estudantil e possuíam dois aspectos: i) reivindicar direitos sociais (moradia, transporte, trabalho, segurança, lazer, saneamento básico etc.) e ii) afirmar a cidadania por meio da luta democrática. Segundo a referida autora, foi a partir desta perspectiva que o Direito à Cidade passou a ser reconhecido no ordenamento jurídico pátrio.

Considerando a importância do espaço urbano para a concretização da dignidade da pessoa humana, e sobretudo para o exercício de Direitos Sociais, a Constituição Federal de 1988 (CF/88) além de reconhecê-lo, definiu a repartição de competências em matéria urbanística.

Dessa forma, compete à União, elaborar e executar planos nacionais e regionais de ordenação do território e de desenvolvimento econômico e social (art. 21, IX), bem como diretrizes para o desenvolvimento urbano (art. 21, XX), aos Estados, atribuiu competência para complementar as normas gerais estabelecidas pela União (art. 24), e aos Municípios a competência para executar o Plano Diretor, o principal instrumento do planejamento das cidades no país. (Art. 30).

Assim, atribuiu-se à União e aos Estados, competências legislativas concorrentes, enquanto ao Município, a CF/88 estabeleceu competência administrativa, pois regula o Direito Urbanístico de modo factual, e o executa conforme as diretrizes estabelecidas pelos demais entes.

Do mesmo modo, a CF/88 estabeleceu, no Capítulo II do Título VII, as diretrizes que devem reger a Política Urbana nacional, cujo objetivo reside em ordenar o pleno desenvolvimento das funções sociais da cidade e garantir o bem-estar de seus habitantes, conforme se lê em seu artigo $182^{3}$. Essas diretrizes da Política Urbana são: “o conjunto de situações urbanísticas de fato e de direito a serem alvejadas pelo Poder Público no intuito de constituir, melhorar, restaurar e preservar a ordem urbanística, de modo a assegurar o bem-estar das comunidades em geral". (CARVALHO FILHO, 2013, p. 27).

Contudo, tais diretrizes somente foram estabelecidas treze anos depois, por meio do Estatuto da Cidade (2001), que, fundamentado nos princípios de planejamento participativo e da

\footnotetext{
${ }^{3}$ Art. 182. A política de desenvolvimento urbano, executada pelo Poder Público municipal, conforme diretrizes gerais fixadas em lei, tem por objetivo ordenar o pleno desenvolvimento das funções sociais da cidade e garantir o bem- estar de seus habitantes. (BRASIL, 1988).
} 
função social da propriedade, instituiu uma série de instrumentos urbanísticos ${ }^{4}$, com o objetivo de concretizar os pressupostos da Política Urbana, e deste modo proporcionar um processo de urbanização mais eficiente, além da melhoria da qualidade de vida da coletividade.

Nesse sentido, de acordo com Carvalho Filho (2013) o principal instrumento da Política de desenvolvimento e expansão urbana é o Plano Diretor. Para o autor, a própria CF/88 classificou-o como responsável por garantir a minoração dos acentuados antagonismos sociais, econômicos e espaciais dos centros urbanos brasileiros. Além disso, conforme o artigo 182, § $1^{\circ}$ deve ser aprovado pela Câmara Municipal, ser estabelecido por lei, é obrigatório para cidades com mais de vinte mil habitantes e parâmetro para avaliação da função social da propriedade.

Considerando a relevância do Plano Diretor e sua natureza como um processo político de tomada de decisão acerca do espaço urbano municipal, torna-se indispensável a participação popular durante sua elaboração. Isto porque, o referido instrumento figura como norteador de combate às desigualdades sociais. Assim, “o Plano Diretor, nos termos dados pela Constituição Federal e pelo Estatuto da Cidade, é peça chave para o enfrentamento desses problemas, contribuindo para minimização do quadro de desigualdade urbana instalado, quando elaborado e implementado de forma eficaz”. (SANTOS JÚNIOR; SILVA; SANT’ANA, 2011, p. 14).

Percebe-se, desta forma, que no âmbito jurídico os pressupostos do Direito à Cidade possibilitam a compreensão de um espaço urbano propício para a promoção da igualdade, da inclusão, da participação popular e principalmente da dignidade da pessoa humana. Sua finalidade é a realização do bem estar dos indivíduos e a melhoria da sua qualidade de vida. Assim, é composto pela garantia dos direitos que fundamentam a função social da cidade e por possuírem natureza prestacional, dependem impreterivelmente da atuação do Poder público para sua concretização.

Sendo assim, é fundamental a compreensão dos elementos de urbanização que devem, compor o Plano Diretor, e que fundamentam as diretrizes para a construção de um espaço urbano

\footnotetext{
${ }^{4}$ No artigo $4^{\circ}$ do Estatuto foram conformados os instrumentos da política urbana em geral, divididos, por sua vez, em planos e projetos de planejamento, institutos tributários e financeiros e institutos jurídicos e políticos propriamente ditos. Por exemplo: as zonas especiais de interesse social, as operações urbanas, a outorga onerosa do direito de construir e a transferência do direito de construir, o Parcelamento, Edificação ou Utilização Compulsórios e o IPTU progressivo no tempo e etc. (BRASIL, 2001).
} 
inclusivo e acessível. Haja vista, que, por meio da implantação de ações voltadas a assegurar a acessibilidade na cidade democratiza-se seu uso e promove-se a dignidade humana.

\section{ELEMENTOS DE URBANIZAÇÃO À LUZ DA LEI BRASILEIRA DE INCLUSÃO DA PESSOA COM DEFICIÊNCIA - LEI 13.146/2015.}

Tendo em vista a importância do Plano Diretor para a realização do projeto constitucional de Política Urbana, e com o objetivo de assegurar o bem-estar de todos os indivíduos nas cidades, a Lei no 13.146/15 que instituiu a Lei Brasileira de Inclusão da Pessoa com Deficiência (LBIPD), estabeleceu aspectos urbanísticos em seu texto normativo. Entre os benefícios oriundos do novo diploma legal, ganhou ênfase o compromisso do país em incentivar a construção de cidades inclusivas que viabilizem a acessibilidade ${ }^{5}$ a seus cidadãos.

Reconhecida pelo avanços na proteção da dignidade da pessoa com deficiência ${ }^{6}$, a referida lei promoveu alterações na política de gestão urbana do país, pois ensejou mudanças na Lei da Acessibilidade. A LBIPD, segundo seu artigo $1^{\circ}$ estabeleceu "normas gerais e critérios básicos para a promoção da acessibilidade das pessoas portadoras de deficiência ${ }^{7}$ ou com mobilidade reduzida ${ }^{8}$. E definiu novas diretrizes para as normas de acessibilidade que passaram a nortear os elementos de urbanização a serem implementados pelas cidades. (BRASIL, 2015).

Conforme dito, o texto normativo que elenca os elementos de urbanização encontram-se positivados no capítulo II da Lei de Acessibilidade e sofreram mudanças, assim, passaram a ter uma nova redação. Para melhor leitura e compreensão das alterações, elaborou-se o quadro 1 a seguir:

Quadro 1. Mudanças no artigo $3^{\circ}$ da Lei no $10.098 / 2008$

\footnotetext{
${ }^{5}$ O Decreto $\mathrm{n}^{\mathrm{o}}$ 5.296, de 2 de dezembro de 2004, define acessibilidade como: "condição para utilização, com segurança e autonomia, total ou assistida, dos espaços, mobiliários e equipamentos urbanos, das edificações, dos serviços de transporte e dos dispositivos sistemas e meios de comunicação e informação, por pessoa portadora de deficiência ou com mobilidade reduzida." (BRASIL, 2004).

${ }^{6} \mathrm{O}$ art. $2^{\circ}$, III da Lei 13.146/15 define pessoa com deficiência como: "aquela que tem impedimento de longo prazo de natureza física, mental, intelectual ou sensorial, o qual, em interação com uma ou mais barreiras, pode obstruir sua participação plena e efetiva na sociedade em igualdade de condições com as demais pessoas.”(BRASIL, 2015).

${ }^{7}$ Utilizou-se a transcrição literal do artigo, apesar de reconhecer o erro contido na expressão.

${ }^{8}$ A definição de "pessoa com mobilidade reduzida" está prevista na Lei n ${ }^{\circ}$ 10.098/00 (art. $2^{\circ}$, IV), como "aquela que tenha, por qualquer motivo, dificuldade de movimentação, permanente ou temporária, gerando redução efetiva da mobilidade, da flexibilidade, da coordenação motora ou da percepção, incluindo idoso, gestante, lactante, pessoa com criança de colo e obeso". (BRASIL, 2000).
} 


\section{REDAÇÃO ORIGINAL}

Art. $3^{\circ} \mathrm{O}$ planejamento e a urbanização das vias públicas, dos parques e dos demais espaços de uso público deverão ser concebidos e executados de forma a torná-los acessíveis para as pessoas portadoras de deficiência ou com mobilidade reduzida.

\section{REDAÇÃO DADA PELA LEI No 13.146, DE 2015}

Art. $3^{\circ} \mathrm{O}$ planejamento e a urbanização das vias públicas, dos parques e dos demais espaços de uso público deverão ser concebidos e executados de forma a torná-los acessíveis para todas as pessoas, inclusive para aquelas com deficiência ou com mobilidade reduzida.

Parágrafo único. $O$ passeio público, elemento obrigatório de urbanização e parte da via pública, normalmente segregado e em nível diferente, destinase somente à circulação de pedestres e, quando possível, à implantação de mobiliário urbano e de vegetação.

Fonte: Elaborado pelo autor, com base na Lei 13.146/15 (BRASIL, 2015)

Da leitura, nota-se duas mudanças: Primeiramente, na inclusão da expressão "para todas as pessoas" no caput do artigo, dessa forma, o novo texto se dirige a todos igualitariamente, e não apenas às pessoas com deficiência ou mobilidade reduzida. Com isto, superou a perspectiva integracionista destes grupos, e adotou um modelo inclusivo. Posteriormente, com a introdução do parágrafo único, foi instituído o conceito e a obrigatoriedade do espaço de passeio público, com vistas a viabilizar o exercício da mobilidade e do Direito à Cidade por todos.

Além das alterações promovidas na Lei da Acessibilidade, a LBIPD modificou alguns regramentos contidos no Estatuto da Cidade, uma vez que, introduziu disposições e indicou novos parâmetros para o planejamento urbano. Deste modo, no artigo $3^{\circ}$ que trata sobre a competência da União a redação dos incisos III e IV assim passou a dispor:

Art. $3^{\circ}$ Compete à União, entre outras atribuições de interesse da Política Urbana:

III - promover, por iniciativa própria e em conjunto com os Estados, o Distrito Federal e os Municípios, programas de construção de moradias e melhoria das condições habitacionais, de saneamento básico, das calçadas, dos passeios públicos, do mobiliário urbano e dos demais espaços de uso público;

IV - instituir diretrizes para desenvolvimento urbano, inclusive habitação, saneamento básico, transporte e mobilidade urbana, que incluam regras de acessibilidade aos locais de uso público; (BRASIL, 2015, grifo nosso).

Ressalta-se que, ao promover tais mudanças, a LBIPD contribuiu para o reconhecimento da necessidade de assegurar e promover, de forma isonômica o exercício dos direitos e das 
liberdades fundamentais da pessoa com deficiência, permitindo sua inclusão social e cidadania. Para tanto, incluiu ainda o $\$ 3^{\circ}$ no artigo 41 do Estatuto da Cidade, a seguir:

$\S 3^{\circ}$ As cidades de que trata o caput deste artigo devem elaborar plano de rotas acessíveis, compatível com o plano diretor no qual está inserido, que disponha sobre os passeios públicos a serem implantados ou reformados pelo poder público, com vistas a garantir acessibilidade da pessoa com deficiência ou com mobilidade reduzida a todas as rotas e vias existentes, inclusive as que concentrem os focos geradores de maior circulação de pedestres, como os órgãos públicos e os locais de prestação de serviços públicos e privados de saúde, educação, assistência social, esporte, cultura, correios e telégrafos, bancos, entre outros, sempre que possível de maneira integrada com os sistemas de transporte coletivo de passageiros. (BRASIL,2015, grifo nosso).

A partir da leitura do novo dispositivo, nota-se que a adequação do Plano Diretor a estes preceitos gerais, tornou-se obrigatória. Dessa forma, os Municípios devem elaborar um Plano de Rotas Acessíveis capaz de garantir passeios públicos e acessibilidade no espaço urbano, sobretudo, nos ambientes de intensa circulação de pedestres e de atendimento ao público, sem desconsiderar a integração com o transporte coletivo. Neste sentido, segundo a Associação Brasileira de Normas Técnicas, o conceito de rota acessível é:

A rota acessível é um trajeto contínuo, desobstruído e sinalizado, que conecta os ambientes externos e internos de espaços e edificações, e que pode ser utilizada de forma autônoma e segura por todas as pessoas. A rota acessível externa incorpora estacionamentos, calçadas, faixas de travessias de pedestres (elevadas ou não), rampas, escadas, passarelas e outros elementos da circulação. A rota acessível interna incorpora corredores, pisos, rampas, escadas, elevadores e outros elementos da circulação. (ABNT - NBR 9050/15).

Pelo exposto, verifica-se, que o advento da LBIPD promoveu modificações na Lei da Acessibilidade e no Estatuto da Cidade e estabeleceu o dever de compatibilidade do Plano Diretor com suas diretrizes gerais. Com isto, incluiu de maneira definitiva as discussões acerca da acessibilidade no Direito Urbanístico e consagrou como indispensável, a observância de suas diretrizes para a construção de espaços urbanos inclusivos e que viabilizem o exercício de Direitos Fundamentais de todos.

Por outro lado, considerando que o Plano Diretor de Pelotas, instituído por meio da Lei $\mathrm{n}^{\circ}$ 5.502, de 11 de setembro de 2008 foi recentemente revisto por intermédio da Lei $\mathrm{n}^{\mathrm{o}} 6.636$, de 03 de outubro de 2018, e que tal instrumento é um importante meio para a construção de um espaço 
urbano inclusivo, passa-se a uma investigação acerca do tratamento dispensado à acessibilidade e ao Plano de Rotas Acessíveis no Plano Diretor da cidade. O objetivo é averiguar, se houve a devida adequação à Lei Brasileira de Inclusão da Pessoa com Deficiência e contribuir com a temática.

\section{O PLANO DIRETOR DE PELOtaS, ACESSIBILIDAdE E O PLANO DE ROTAS ACESSÍVEIS}

Pelotas é um município brasileiro, localizado no sul do Estado do Rio Grande Sul, tem população estimada em aproximadamente 341.648 habitantes, que convivem em um território de $1.609,708 \mathrm{~km}^{2}$ e densidade demográfica de 203,89 hab $/ \mathrm{km}^{2}$, com PIB per capita de R $22.629,54$ e índice de desenvolvimento humano (IDH) - 0,739. Em quantidade populacional, figura como $3^{\circ}$ cidade mais populosa do Estado (RS), a $69^{\circ}$ no país, além de ocupar a $163^{\circ}$ posição no ranking que mensura o IDH dos 496 municípios do Rio Grande do Sul. (IBGE, 2010).

Considerando os dados do Censo do IBGE de 2010 que identificou pessoas com alguma deficiência, 87.295 pessoas residentes no município relataram possuir algum grau de dificuldade em pelo menos uma das habilidades investigadas (enxergar, ouvir e andar) ${ }^{9}$ ou ter alguma deficiência mental ou intelectual ${ }^{10}$, o que representa, $25 \%$ de seus habitantes. De acordo com instituto, a cidade possuía, à época, o serviço de transporte coletivo intramunicipal, cuja frota estava parcialmente adaptada. (IBGE, 2010). Assim, com o objetivo de proporcionar uma melhor visualização e compreensão dos dados, elaborou-se a tabela 1 a seguir, onde é possível identificar o tipo de deficiência, seu grau e os números absolutos e relativos da pesquisa.

Tabela 1. Pessoas com alguma deficiência em Pelotas/RS

PESSOAS COM ALGUM TIPO DE DEFICIENCIA EM PELOTAS - IBGE 2010

\footnotetext{
${ }^{9}$ Ao perguntar à população sobre essa questão, o IBGE procurou captar a percepção sobre a dificuldade em ouvir, enxergar e caminhar ou subir escadas, mesmo contando com facilitadores como aparelhos auditivos, lentes de contato e bengalas. Seguindo orientações internacionais, considera-se "pessoa com deficiência" os indivíduos que responderem ter pelo menos muita dificuldade em uma ou mais questões. (IBGE, 2010).

${ }^{10}$ A pesquisa buscou também identificar deficiência intelectual e mental através da compreensão sobre a dificuldade em realizar atividades habituais. Não foram consideradas neste quesito as perturbações, doenças ou transtornos mentais como autismo, neurose, esquizofrenia e psicose. (IBGE, 2010).
} 
Pablo Alan Jenison Silva \& Felisberto Ferreira de Freitas Júnior

\begin{tabular}{cccccccc}
\hline $\begin{array}{c}\text { TIPO DE } \\
\text { DEFICIENCIA }\end{array}$ & $\begin{array}{c}\text { NÃO } \\
\text { CONSEGUE } \\
\text { DE MODO } \\
\text { ALGUM }\end{array}$ & $\%$ & $\begin{array}{c}\text { GRANDE } \\
\text { DIFICULDADE }\end{array}$ & $\%$ & $\begin{array}{c}\text { ALGUMA } \\
\text { DIFICULDADE }\end{array}$ & $\%$ & TOTAL \\
\hline Visual & 814 & $1 \%$ & 11.452 & $18 \%$ & 52.044 & $81 \%$ & 64.310 \\
\hline Auditiva & 505 & $2 \%$ & 4.296 & $20 \%$ & 17.138 & $78 \%$ & 21.939 \\
\hline Motora & 1.750 & $6 \%$ & 8.753 & $30 \%$ & 18.200 & $63 \%$ & 28.703 \\
\hline
\end{tabular}

Fonte: elaborado pelo autor, com dados do IBGE 2010

Assim, considerando que 1/4 da população pelotense possui algum tipo de deficiência, é imprescindível a adoção de políticas de inclusão no espaço urbano, já que "a acessibilidade, ao ser parte integrante e fundamental da dinâmica e do funcionamento das cidades, passa a ser um elemento que contribui para a qualidade de vida urbana, na medida em que facilita o acesso da população aos serviços e equipamentos urbanos”. (CARDOSO; MATOS, 2007, s.p).

Além disso, nota-se a necessidade do Poder Público Municipal quando da elaboração do planejamento urbano de Pelotas, adote meios para assegurar a acessibilidade, e dessa forma, reforce medidas e instrumentos legais para efetivação do Direito Fundamental de viver e gozar de um espaço urbano inclusivo.

O Município de Pelotas, antes mesmo da entrada em vigor do Estatuto da Cidade (Lei 10.257/01), já demonstrava compromisso com a discussão do planejamento urbano do município. O primeiro Conselho Municipal do Plano Diretor, foi instituído por meio da Lei $\mathrm{n}^{\mathrm{o}} 1.289$, de 14 de dezembro de 1963, cuja competência foi estabelecida em seu artigo $1^{\circ}$, a seguir:

Art. $1^{\circ}$ - É criado o Conselho Municipal do Plano Diretor, ao qual compete: I - Colaborar com a equipe técnica incumbida da elaboração do Plano Diretor da cidade, surgindo soluções para os problemas urbanos; II - Divulgar o Plano nas entidades por eles representadas; III - Relatar e opinar, a pedido do Executivo Municipal, em assuntos relativos ao mesmo, inclusive loteamentos, situados dentro ou fora das áreas traçada pelo Plano Diretor; IV - Zelar pela sua aplicação, independentemente de mudanças no Governo Municipal. (PELOTAS, 1963).

Resultado do trabalho de tal Conselho, o primeiro Plano Diretor do município foi sancionado em 30 de maio de 1968, por intermédio da Lei $\mathrm{n}^{\mathrm{o}} 1.672$ e posteriormente, substituído, pela Lei $\mathrm{n}^{\mathrm{o}}$ 2.565, de 26 de agosto de 1980. Em 11 de setembro de 2008, à luz da CF/88, da LBIPD (2000) e do Estatuto da Cidade (2001), promulgou-se o III Plano Diretor de 
Pelotas, a Lei Municipal $\mathrm{n}^{\mathrm{o}}$ 5.502, que em razão do dever de revisão decenal ${ }^{11}$, foi alterado pela Lei $\mathrm{n}^{\circ}$ 6.634, de 03 de outubro de 2018. O Plano Diretor vigente estabelece em seu artigo $2^{\circ}$ :

Art. 2 - O Plano Diretor Municipal de Pelotas é o instrumento básico da política de desenvolvimento municipal, abrangendo os aspectos físicos, sociais, econômicos e administrativos do crescimento da cidade, visando a orientação da atuação do Poder Público e da iniciativa privada, bem como ao atendimento das necessidades da comunidade, sendo a principal referência normativa para as relações entre o cidadão, as instituições e o espaço físico municipal. (PELOTAS, 2008, grifo nosso).

Além de trazer a conceituação do Plano Diretor no âmbito municipal, o artigo confirma o objetivo da administração local em aliar o alcance dos aspectos físicos, econômicos e administrativos com aspectos sociais e dessa forma garantir o atendimento das necessidades dos seus cidadãos, no exercício de seu Direito à Cidade. Sendo assim, por meio de consulta ao Plano Diretor de Pelotas, buscou-se identificar o tratamento dado à acessibilidade e quais ações foram formuladas a partir de sua elaboração. A análise resultou na construção do quadro 2, a seguir:

Quadro 2: Acessibilidade no Plano Diretor de Pelotas

\begin{tabular}{|c|c|}
\hline $\begin{array}{l}\text { Art. } 7 \text { - A política de ordenamento e desenvolvimento } \\
\text { territorial do município deve se pautar pelas seguintes } \\
\text { diretrizes gerais: [...] } \\
\text { III - Promover a acessibilidade universal, como forma } \\
\text { de garantir a inclusão das pessoas portadoras de } \\
\text { necessidades especiais ou mobilidade reduzida; }\end{array}$ & $\begin{array}{l}\text { O artigo estabelece como diretriz a promoção da } \\
\text { acessibilidade universal. Porém, não a conceitua e ainda } \\
\text { utiliza o termo, "pessoa portadora deficiência", apesar da } \\
\text { consolidação do Estatuto da pessoa com deficiência. } \\
\text { (Lei. 13.146/2015). }\end{array}$ \\
\hline $\begin{array}{l}\text { Art. } 101 \text { - Constituem definições da Mobilidade Urbana } \\
\text { e do Sistema Viário: } \\
\text { I - A Mobilidade Urbana no território municipal é } \\
\text { definida e estruturada pelo conjunto de políticas de } \\
\text { transporte e circulação que visam proporcionar o amplo } \\
\text { acesso ao espaço urbano, garantindo acessibilidade } \\
\text { universal, eqüidade, segurança e a circulação de pessoas } \\
\text { e de veículos de forma ordenada territorialmente; }\end{array}$ & $\begin{array}{l}\text { Considerando o Sistema de Planejamento para Pelotas, o } \\
\text { artigo } 18 \text { estabelece seu Plano de Mobilidade Urbana, } \\
\text { contudo, não estipulou prazo para sua implementação. O } \\
\text { artigo 101, define a mobilidade urbana e prevê a } \\
\text { acessibilidade universal como um de seus elementos. }\end{array}$ \\
\hline $\begin{array}{l}\text { Art. } 102 \text { - Constituem diretrizes amplas da mobilidade } \\
\text { urbana e sistema viário: } \\
\text { VI - Melhorar a acessibilidade da população aos locais } \\
\text { de emprego, de serviços e de equipamentos de lazer; } \\
\text { XX - Revitalizar e construir passeios para qualificar a } \\
\text { circulação de pedestres, assegurando a acessibilidade } \\
\text { universal, em especial na Meso-Região CE 3, conforme } \\
\text { mapa U-06 anexo à presente lei; } \\
\text { XXI - Proporcionar a criação de rotas acessíveis, }\end{array}$ & $\begin{array}{l}\text { Ao estabelecer diretrizes para a Mobilidade Urbana, o } \\
\text { legislador municipal atentou-se para a questão da } \\
\text { acessibilidade, apontou ações como a revitalização e } \\
\text { construção de passeios, para como meio de garantir a } \\
\text { acessibilidade universal. Além disso, comprometeu-se } \\
\text { em viabilizar o transporte coletivo adaptado para pessoas } \\
\text { com deficiência. (apesar de utilizar termo errôneo). } \\
\text { Destaca-se, ainda, que foi a primeira vez que mencionou } \\
\text { a o termo "rotas acessíveis", no Plano Diretor, um dos }\end{array}$ \\
\hline
\end{tabular}

${ }^{11}$ No artigo 40, $\S 3^{\circ}$ do Estatuto da Cidade estabelece que: a lei que instituir o plano diretor deverá ser revista, pelo menos, a cada dez anos. (BRASIL, 2015).

Revista de Direito Urbanístico, Cidade e Alteridade | e-ISSN: 2525-989X | Belém | v. 5 | n. 2 |

p. 55 - 71 | Jul/Dez. 2019. 
conforme norma, conectadas ao sistema de transporte coletivo;

XIV - Garantir a utilização do transporte coletivo municipal pelos portadores de necessidades especiais com qualificação;

Art. 119 - São Projetos Especiais que complementam o Sistema Temático do Modelo Espacial os seguintes:

XV - Implantação das rotas acessíveis;

Art. 176 - A concepção dos projetos de parcelamentos de solo urbano, em todas suas classificações, privados e públicos, devem atender aos princípios do desenho universal, os quais tratam da acessibilidade universal, e demais legislações e normas pertinentes, bem como as disposições da presente Lei, no que couber.

Art. 178 - Todo loteamento deverá comportar rotas acessíveis para portadores de necessidades especiais, entre as unidades habitacionais e os espaços de uso coletivo, observadas as disposições dos planos municipais de rotas acessíveis.

Art. 188 - Incumbe ao proprietário a implantação de infraestrutura do parcelamento, nas seguintes condições:

II - Obras Complementares - são aquelas constantes do projeto executivo aprovado na Prefeitura Municipal e demais organismos afins, expressas em cronograma próprio, a serem executadas em Módulos Autônomos, compostas no mínimo dos seguintes itens:

g) Execução dos dispositivos que garantam acessibilidade universal, a saber: rampas nos passeios, elevação das vias, alargamentos nos passeios e outras medidas apontadas na análise da viabilidade;

Art. 228 - A premissa básica para o dimensionamento do lote para um parcelamento em AEIS levará em conta tamanho, que permita a implantação de unidade habitacional, térrea ou assobradada, ocupando o terreno de forma a:

I - Permitir a acessibilidade ao lote e edificação;

Art. 249 - O Estudo de Impacto de Vizinhança - EIV será executado de forma a contemplar os efeitos positivos e negativos do empreendimento ou atividade quanto à qualidade de vida da população residente na área e em suas proximidades, incluindo a análise das seguintes questões:

V - Considerações contemplando os efeitos positivos e negativos do empreendimento, incluindo, no mínimo:

e) A geração de tráfego e a demanda por transporte público, sistemas de circulação incluindo tráfego gerado, acessibilidade, estacionamentos, carga e descarga, embarque e desembarque;

Art. 309 - Constituem infrações de atividades passíveis de penalidades:

VII - Realizar atividade comercial sem acessibilidade universal e sem sanitário adaptado a portadores de necessidades especiais: multa de 3 (três) URM; pontos em discussão neste trabalho.

Estabeleceu como projeto especial a implantação de rotas acessíveis, sem contudo trazer o conceito da mesma e estipular um prazo para sua implantação.

Neste artigo, o legislador municipal, apontou o cuidado em atender os princípios que circundam a acessibilidade universal e as legislações afins, quando da criação de projetos de um dos principais instrumentos de expansão urbana, o planejamento do solo.

No artigo 178, foi estabelecida a obrigatoriedade de rotas acessíveis à pessoa com deficiência em todo loteamento, infere-se que o objetivo é promover condições dignas de moradia. Para tanto, estabelece observância ao Plano Municipal de Rotas Acessíveis.

Neste artigo, inciso e alínea, ao proprietário determinouse a imprescindibilidade da adoção de meios que viabilizem a acessibilidade universal quando da implantação de infraestrutura de parcelamento em obras complementares.

Considerando a necessidade de estabelecer condições de acessibilidade e de moradia digna, foi determinado a observância de dimensões mínimas quando do parcelamento de lotes em Área Especial de Interesse Social.

Ao instituir a maneira como será realizado o Estudo de Impacto de Vizinhança, foi estabelecido que entre os critérios mínimos de avaliação deve ser considerado a demanda por acessibilidade. Ao que parece, a inclusão da acessibilidade não teve como o objetivo principal a salvaguarda da mobilidade da pessoa com deficiência.

Único artigo que trata sobre acessibilidade que sofreu alteração com o a edição da Lei $n^{\circ}$ 6.634. No caso, houve a inclusão do inciso VII que estabelece multa à empresários que não observem a necessidade de garantir acessibilidade em sua atividade comercial. 
Fonte: elaborado pelo autor, com base na Lei $n^{\circ} 5.502 / 08$ e Lei $n^{\circ} 6.634 / 2018$

Considerando a importância do Plano Diretor, como ferramenta para a construção de cidades inclusivas, conforme já discutido, percebe-se que, o tratamento dado à acessibilidade no Plano Diretor de Pelotas é insuficiente para garantir os objetivos estabelecidos na Lei da Acessibilidade (2000), no Estatuto da Cidade (2001) e na Lei Brasileira de Inclusão da Pessoa com Deficiência (2015), tampouco observou seus princípios quando de sua revisão.

Infere-se isto, em virtude de que, muito embora, o referido Plano tenha reconhecido a importância da inclusão, incorporado alguns instrumentos e ações para alcançá-la, ao referir-se a seus destinatários, utiliza uma lógica integracionista. É o que se nota, quando o texto os trata de maneira determinada ou como grupo segregado. Além disso, persistiu em utilizar o termo "pessoa portadora de deficiência" o que, resta ultrapassado e equivocado.

Do mesmo modo, apesar de ter previsto planos de planejamento, como o Plano de Mobilidade Urbana e o Plano de Rota Acessível, estas ações não estão nitidamente delimitadas, assim, não há metas e prazos para serem executados. Apesar de consagrados em setembro de 2008 até agosto de 2019 restam inexistentes. Assim como, a não estipulação de fiscalização ou meios de avaliação do cumprimento do legislado. Conforme se lê no Inventário de Mobilidade Urbana de Pelotas, realizado pela prefeitura em 2018.

A Lei federal de número 10.098 , de 19 de dezembro de 2000 estabeleceu normas gerais
e critérios básicos para a promoção da acessibilidade das pessoas com deficiência ou
com mobilidade reduzida, mas uma ação prática das administrações municipais está
demorando a se concretizar. Em Pelotas não é muito diferente. [...] Uma ação
anterior de alargamento de calçadas nas esquinas para incorporar rampas de
acesso foi realizada, porém de forma pontual, não estabelecendo uma rede contínua
de acessibilidade. O piso táctil passou a ser exigência legal municipal a partir de
dezembro de 2008, mas apenas a partir de 2013 a Prefeitura adotou política de
fiscalização. (PELOTAS, 2018, grifo nosso).

Em relação Plano de Mobilidade Urbana, apesar de ter sido concebido no ano de 2008 como elemento do III Plano Diretor de Pelotas, a nomeação de servidores e técnicos para sua elaboração só efetivou-se em 25 de setembro de 2017, através da Portaria 048/2017. A apresentação de uma versão da proposta do Plano de Mobilidade Urbana de Pelotas - PlanMob foi realizada em abril de 2019 e ainda encontra-se em fase de discussões (PELOTAS, 2019).

Revista de Direito Urbanístico, Cidade e Alteridade | e-ISSN: 2525-989X | Belém | v. 5 | n. 2 |

p. 55 - 71 | Jul/Dez. 2019.

67 
Por outro lado, o Plano de Rotas Acessíveis, item obrigatório a ser adotado pelo Plano Diretor, conforme o $\$ 3^{\circ}$ do artigo 41 do Estatuto da Cidade, constatou-se que, apesar de ser previsto nas diretrizes amplas (art. 102, XXI) e como projeto especial do Sistema Temático do Modelo Espacial (art. 119) ambos do Plano Diretor de Pelotas, o mesmo não foi executado.

Portanto, passados mais de 10 anos da entrada em vigor do III Plano Diretor de Pelotas, e sua revisão decenal em 2018, ainda existem muitos desafios a serem superados, para que seja possível viabilizar o que nele se estabeleceu. Contudo, é possível reconhecer que já foram dados alguns passos para a concretização do direito a uma cidade inclusiva. Isto porque, além dos instrumentos discutidos a legislação municipal de Pelotas já conta com as seguintes leis:

Quadro 3. Legislação acerca da acessibilidade em Pelotas/RS

\begin{tabular}{|l|l|}
\hline Lei 5.759/10 & $\begin{array}{l}\text { Dispõe sobre a instalação de sinal sonoro nos semáforos para atender aos portadores de deficiência } \\
\text { visual. }\end{array}$ \\
\hline Lei 6.210/15 & $\begin{array}{l}\text { Torna obrigatória a utilização de sinalização vertical de regulamentação em estacionamentos de } \\
\text { acesso público para as vagas destinadas a deficientes físicos, idosos e gestantes. }\end{array}$ \\
\hline Lei 6.240/15 & $\begin{array}{l}\text { Permite o embarque e desembarque de cadeirantes ou portadores de deficiência com dificuldade de } \\
\text { locomoção, pelo período de 5 minutos, com pisca alerta ligado, em frente à residência, área urbana e } \\
\text { rural, devidamente identificada pelo transporte e trânsito da prefeitura municipal de Pelotas. }\end{array}$ \\
\hline Lei 6.214/15 & $\begin{array}{l}\text { Institui o sistema de acessibilidade às pessoas com dificuldade de locomoção, permanente ou } \\
\text { temporária, nas praias da orla do laranjal, no município de Pelotas, e dá outras providências. }\end{array}$ \\
\hline Lei 6.519/17 & $\begin{array}{l}\text { Determina que todas as vagas de estacionamento (públicas e privadas) destinadas aos veículos das } \\
\text { pessoas portadoras de deficiência física ou necessidades especiais, sejam disponibilizadas durante o } \\
\text { período de 24 horas. }\end{array}$ \\
\hline
\end{tabular}

Fonte: Elaborado pelo autor

\section{Considerações Finais}

Considerando as conquistas das discussões acerca da acessibilidade como pauta social e seus reflexos no ordenamento jurídico brasileiro, o presente artigo objetivou realizar a identificação das alterações promovidas na Lei da Acessibilidade e no Estatuto da Cidade com o advento da LBIPD. Além disso, averiguar, em que medida o III Plano Diretor de Pelotas, adequou-se as diretrizes estabelecidas pelo novo marco legal e assim contribuir com tal debate.

A partir de um breve levantamento acerca do Direito à Cidade e do Plano Diretor, realizada com base nos conceitos definidos pela literatura, verificou-se que sua origem remete à ideia de transdisciplinaridade e que foi reconhecido recentemente pelo Direito. Ademais, a 
avaliação do sistema de repartição de competências, permite afirmar que o município, no contexto da Política Urbana e como ente político dotado de autonomia, é o responsável pela garantia de políticas públicas para a efetivação do Direito à Cidade, dentre os quais destaca-se a acessibilidade, e para tanto deve elaborar seu Plano Diretor.

Percorrendo os elementos de urbanização positivados na Lei Brasileira de Inclusão da Pessoa com Deficiência, constatou-se, que sua inserção na ordem jurídica nacional promoveu modificações na Lei de Acessibilidade e no Estatuto da Cidade. Assim como, estabeleceu o dever de compatibilidade do Plano Diretor com suas diretrizes gerais. Com isto, incluiu de maneira definitiva as discussões acerca da acessibilidade no Direito Urbanístico e consagrou como indispensável, a observância de suas diretrizes para a construção de espaços urbanos inclusivos e que viabilizem o exercício de Direitos Fundamentais.

Identificou-se que Município de Pelotas, antes mesmo da entrada em vigor do Estatuto da Cidade, já demonstrava compromisso com a discussão do planejamento urbano do seu território. Todavia, somente passou a prever elementos e ações de acessibilidade, a partir de seu III Plano Diretor, no ano de 2008, que, muito embora, tenha sido elaborado sob a égide da CF/88, da Lei de Acessibilidade, do Estatuto da Cidade e da LBIPD, ainda existem muitos desafios a serem superados, para que seja possível viabilizar o que nele se estabeleceu.

Deste modo, conclui-se que o Direito à Cidade engloba a acessibilidade, uma vez que promove a dignidade da pessoa com deficiência garantindo-lhes Direitos Fundamentais. Além disso, apesar de possuir outras legislações voltadas para a acessibilidade, o Plano Diretor de Pelotas, como principal meio de planejamento da cidade, não se adequou totalmente à LBIPD.

\section{Referências}

ABNT. Associação Brasileira de Normas Técnicas NBR 9050: acessibilidade a edificações, mobiliário, espaços e equipamentos urbanos. Rio de Janeiro, 2015. Disponível em: http://bit.ly/2KpYbK5. Acesso em: 26 de jul. 2019.

BRASIL. Constituição (1988). Constituição da República Federativa do Brasil. Brasília: Senado Federal, 1988.

BRASIL. Lei n. 10.098 de 19 de dezembro de 2000. Estabelece normas gerais e critérios básicos para a promoção da acessibilidade das pessoas portadoras de deficiência ou com 
mobilidade reduzida, e dá outras providências. Disponível em: http://bit.ly/3381Qah. Acesso em: 25 de jul. 2019.

BRASIL. Estatuto da Cidade. Lei 10.257, de 10 de julho de 2001. Regulamenta os arts. 182 e 183 da Constituição Federal, estabelece diretrizes gerais da Política Urbana e dá outras providências. Brasília, Câmara dos Deputados, 2001.

BRASIL. Decreto $\mathbf{n}^{\circ} 5.296$ de 2 de dezembro de 2004. Regulamenta as Leis n 10.048, de 8 de novembro de 2000, que dá prioridade de atendimento às pessoas que especifica, e 10.098, de 19 de dezembro de 2000, que estabelece normas gerais e critérios básicos para a promoção da acessibilidade das pessoas portadoras de deficiência ou com mobilidade reduzida, e dá outras providências. Disponível em: http://bit.ly/2YH1mGp. Acesso em: 16 jul. 2019.

BRASIL. Lei n. 13.146 de 6 de Julho de 2015. Institui a Lei Brasileira de Inclusão da Pessoa com Deficiência (Estatuto da Pessoa com Deficiência). Disponível em: http://bit.ly/2GJxsHe. Acesso em 25.10.2016.

CARTA. Mundial do Direito à Cidade. Fórum Social das Américas - Quito - Julho 2004; Fórum Mundial Urbano - Barcelona - Setembro 2004; V Fórum Social Mundial - Porto Alegre Janeiro 2005. Disponível em: http://bit.ly/2YzzyUs. Acesso em: 25 jul. 2019.

CARDOSO, Leandro; MATOS, Ralfo. Acessibilidade Urbana e Exclusão Social: novas Relações, velhos Desafios. In: Simpósio Nacional de Geografia Urbana, 10., 2007, Florianópolis. Anais... Florianópolis: Degrau Arquitetos Associados S/S, 2007. Disponível em: http://bit.ly/2LYWAOx. Acesso em: 25 jul. 2019.

CARVAlHO FILHO, José dos Santos. Comentários ao Estatuto da Cidade. $5^{\circ}$ ed. São Paulo: Atlas. 2013

GOMES, Ana Maria Isar dos Santos. O Direito à Cidade sob uma perspectiva jurídicosociológica. Revista Direito GV, v. 14, n. 2, p. 492-512, 2018. Disponível em: http://bit.ly/2YksHhv. Acesso em: 15 jul. 2019

IBGE. Instituto Brasileiro de Geografia e Estatística. Censo demográfico: Cidades e Estados. Rio de Janeiro, 2018. Disponível em: http://bit.ly/2SJDNqN. Acesso em: 11de jul. 2019.

LEFEBVRE, Henri. O Direito à Cidade. 5. ed. São Paulo: Centauro, 2008.

PELOTAS. Lei no 1672 de 30 de junho de 1968. Aprova o Plano Diretor e suas diretrizes gerais e dá outras providências.

PELOTAS. Lei no 2565/80 (PDN) de 26 de agosto de 1980. Institui o II Plano Diretor de Pelotas Disponível em: http://bit.ly/2YH7zy7. Acesso em: 23 de jul. 2019 
PELOTAS. Lei $\mathbf{n}^{\mathbf{0}} 1.289$ de 14 de dezembro de 1963. Cria o Conselho Municipal do Plano Diretor. Disponível em: http://bit.ly/2YqgxV8. Acesso em 23 de jul. 2019.

PELOTAS. Lei no 5.502 de 11 de setembro de 2008. Institui o Plano Diretor Municipal e estabelece as diretrizes e proposições de ordenamento e desenvolvimento territorial no município de Pelotas, e dá outras providências. Disponível em: http://bit.ly/2Ys2KfV. Acesso em: 23 jul. 2019.

PELOTAS. Lei $\mathbf{n}^{\circ}$ 6.636 de 03 de outubro de 2018. Altera a Lei no 5.502 de 2008, que institui o Plano Diretor Municipal. Disponível em: http://bit.ly/2Mj1OE2. Acesso em: 23 jul. 2019.

PELOTAS. Relatório do inventário da Mobilidade Urbana de Pelotas. Disponível em: http://bit.ly/2T4K5S3. Acesso em: 26 jul. 2019.

PELOTAS. Plano de Mobilidade Urbana de Pelotas. 2019. Disponível em: http://bit.ly/2M0wT05. Acesso em: 27 jul. 2019.

SANTOS JUNIOR. Orlando Alves dos; SILVA. Renata Helena da; SANT'ANA. Marcel Claudio. Apresentação. In Os planos diretores municipais pós-estatudo da cidade: balanço crítico e perspectivas. SANTOS JUNIOR. Orlando Alves dos; MONTANDON. Daniel Todtmann (orgs.) Rio de Janeiro: Letra Capital: Observatório das Cidades: IPPUR/UFRJ, 2011. Disponível em: http://bit.ly/2SFyFUN.Acesso em: 25 jul. 2019. 